\title{
Principios jurídicos y principios bioéticos. Separación, vinculación, integración
}

\section{Legal and bioethical principles. Separation, connection,} integration

\section{EDUARDO LUIS TINANT*}

Resumen: El objetivo de este trabajo es examinar la relación que existe entre los principios jurídicos y los principios bioéticos, en particular cuando los principios bioéticos enriquecen y complementan los principios jurídicos en la solución del caso concreto. Se acude a aportes anteriores del autor sobre los principios bioéticos como tópicos jurídicos y la creación de la bioética jurídica como rama de la bioética que estudia la regulación jurídica y las proyecciones y aplicaciones jurídicas de la problemática bioética y permite, como se procura aquí, una reflexión crítica sobre las crecientes y fecundas relaciones entre bioética y derecho. Desechada la separación y aun la mera vinculación, se propone una integración interdisciplinaria tendiente a instrumentar la cooperación entre ambos campos: heterointegración, producida por desarrollo de principios comunes y afines. Se concluye que el derecho constituye una materia textual, susceptible de ser analizada desde una perspectiva que no se agota en la mera escritura de la ley, sino que intenta captar la producción de sentido social que se inviste en las diversas manifestaciones de esta disciplina y que abarca distintas prácticas sociales, senda por la que se advierte la necesidad de ampliar los marcos teórico-prácticos para poder transitar la interdisciplinariedad y en la que no debe faltar la bioética desde sus principios.

Palabras clave: Principios jurídicos - principios bioéticos - heterointegración

Summary: This work is intended to establish relationships between legal and bioethical principles especially when bioethical principles complement and enrich legal ones in order to solve a specific case. Prior author's contributions on bioethical principles as legal topics and legal bioethics creation in terms of a branch of bioethics which studies legal regulations as well as legal implementation and scope of bioethical problems are referred, making a critical reflection on growing and fruitful relationships between bioethics and law. An Interdisciplinary integration proposed in order to realize cooperation between both fields rejecting a separation or mere connection is suggested: «hetero integration», an integrating system produced by development of common and related principles. The article concludes stating that law structure is a «textual» subject not just involve on the writing of the law but capable to be analyzed from a social sense point of view, conferred to different manifestation of this discipline together with several social practices; a path

* Doctor en Ciencias Jurídicas y Sociales. Profesor titular de Filosofía del Derecho, director y profesor de la Maestría en Bioética Jurídica, profesor de la Especialización de Derecho de Familia, UNLP. Profesor del Doctorado en Derecho, UBA. Profesor de la Escuela Judicial del Consejo de la Magistratura de la Nación Argentina. Director del Instituto de Filosofía y Sociología del Derecho de la Asociación de Magistrados y Funcionarios Judiciales de La Plata. 
warning by the need to broad theoretical-practical frameworks in order to move towards the interdisciplinarity taking into account bioethics from its foundations.

Keywords: Legal principles - bioethical principles - «hetero integration»

\begin{abstract}
CONTENIDO: I. ÉTICA, DERECHO Y BIOÉTICA.- II. LOS PRINCIPIOS BIOÉTICOS COMO TÓPICOS JURÍDICOS.- III. LA BIOÉTICA JURÍDICA.- IV. PRINCIPIOS JURÍDICOS Y PRINCIPIOS BIOÉTICOS: ¿SEPARACIÓN O VINCULACIÓN?.V. ¿HACIA UNA «HETEROINTEGRACIÓN» PORDESARROLLODEPRINCIPIOS?.VI. CONCLUSIONES,
\end{abstract}

Causae ad invicem sunt causae AXIOMA LATINO

La jurisprudencia es el estudio del derecho a la luz de disciplinas no jurídicas JULIUS STONE

\title{
I. ÉTICA, DERECHO Y BIOÉTICA
}

Aun cuando la ética y el derecho, los dos sistemas normativos necesarios de toda sociedad, se ocupan del comportamiento humano tanto individual, como social, no es fácil establecer el o los modos en que se relacionan entre sí (verbigracia, separación, vinculación) ${ }^{1}$. Dificultad que cabe atribuir, asimismo, a la bioética —en su «núcleo duro» una parte de la ética, mas no toda la ética, y a la vez, si se quiere paradójicamente, algo más que ética-, cuya creciente importancia autoriza a considerarla en el debate.

En tal aproximación es dable apreciar deberes éticos negativos, correlativos a prohibiciones jurídicas, y deberes positivos (de promoción o de virtud), correlativos a obligaciones jurídicas de dar y de hacer o no hacer, así como considerar al derecho positivo el resultado de los sistemas de valores que coexisten en una sociedad. Ya hemos tenido oportunidad de señalar la existencia necesaria de una naturalidad del derecho positivo, pero también de una positividad del derecho natural ${ }^{2}$.

El método (virtud) común en ambas disciplinas es la deliberación en el marco de la prudencia y, por ende, con un mismo término: la toma de decisiones prudentes. La jurisprudencia y la morisprudencia son distintas pero complementarias. Se entiende por deliberación la indagación que culmina con un juicio de elección aplicado a lo que es verdaderamente

1 Para un planteamiento teórico sobre las maneras de interpretar dicha relación por las tesis opuestas de la separación y de la vinculación, puede verse VÁZQUEZ, Rodolfo (comp.). Derecho y moral. Ensayos sobre un debate contemporáneo. Barcelona: Gedisa, 1998.

2 TINANT, Eduardo. «La positividad del derecho natural». Boletín de la Asociación Argentina de Filosofía del Derecho, 13 (1984), pp. 5-6. 
útil, para lo cual el operador tiene que nutrirse en el arte de la polémica y de la persuasión, facilitando la certeza y el convencimiento de los demás acerca de que la decisión (prudencial) asumida es la mejor entre todas las posibles. El hombre prudente es, en general, el que sabe deliberar bien. Como enseña Aristóteles ${ }^{3}$, nadie delibera sobre las cosas que no pueden ser distintas de como son, ni sobre las cosas que el hombre no puede hacer. La ciencia, en cambio, es la concepción de las cosas universales cuya existencia es necesaria; por tal razón, el objeto de la ciencia puede ser demostrado. No así el arte y la prudencia, que solo se aplican a las cosas sujetas a mudanza. La prudencia no se limita a saber las fórmulas generales, sino también todas las soluciones particulares, porque es práctica, porque obra, y la acción se aplica al pormenor de las cosas. También Tomás de Aquino supo señalar que (Suma Teológica: II-II, c.49.a.1), la prudencia trata de las acciones contingentes y que en estas no puede el hombre regirse por la verdad absoluta y necesaria, sino por lo que sucede comúnmente 4 .

Para construir un «buen derecho», pues, hay que utilizar argumentos morales (un resultado estrictamente jurídico es a la vez rigurosamente moral). Remedando lo que Immanuel Kant sostuviera ${ }^{5}$, al vincular estrechamente intuición y concepto en la construcción de un objeto lógico de conocimiento, «el derecho sin la ética es ciego, y la ética sin el derecho resulta, al menos en parte, vacía». No es casual que un neokantiano de Baden, Gustav Radbruch, expresara asimismo ese doble vínculo: «La moral es el fundamento sobre que descansa la validez del derecho, porque el hacer posible la moral constituye una meta del orden jurídico» ${ }^{6}$.

Además, si aceptamos con George Nahknikian ${ }^{7}$, de una parte, que los interrogantes icuáles son los ideales a los que debemos tratar de adecuar el orden jurídico?, ¿qué debe ofrecer este orden a los hombres cuya conducta regula? son inherentes a la denominada «jurisprudencia ética», y de otra, que la ética normativa (filosofía moral) es aquella rama de la filosofía que trata de descubrir, justificar y formular principios normativos objetivos (reglas de conducta), creemos estar en condiciones de hallar normas con fundamento filosófico (principios jurídicos). Normas que permitan apreciar y criticar las normas jurídicas y examinar el grado de relación que tales principios jurídicos mantienen con los principios bioéticos.

3 ARIStóteles. Moral a Nicómaco. Prólogo de Luis Castro Nogueira. Madrid: Espasa-Calpe, 1978, pp. 115-118.

4 SANTO TOMÁs. Suma Teológica. Madrid: Espasa-Calpe, 1979, II-II, c. 49, a.1.

5 KANT, Immanuel. Crítica de la razón pura. Noticia preliminar sobre Kant y su obra de Juan B. Bergua. Madrid: Bergua, 1934, p. 216.

6 RADBRUCH, Gustav. Introducción a la filosofía del derecho. México: FCE, 1974, pp. 53/56.

7 NAHKNIKIAN, George. El derecho y las teorías éticas contemporáneas. Buenos Aires: Centro Editor de América Latina, Colección Filosofía y Derecho, 1968, pp. 3-10.

PRINCIPIOS

JURÍDICOS Y

PRINCIPIOS

BIOÉTICOS.

SEPARACIÓN,

VINCULACIÓN,

INTEGRACIÓN

LEGAL AND

BIOETHICAL

PRINCIPLES.

SEPARATION,

CONNECTION,

INTEGRATION 
La bioética, actividad pluridisciplinar que, en sustancia, procura armonizar el uso de las ciencias biomédicas y sus tecnologías con los derechos humanos, en relación con los valores y principios éticos universalmente proclamados ${ }^{8}$, se encuentra hoy en la encrucijada entre la manipulación de la vida y la atención de la salud y el bienestar de las personas, que incluye la necesidad de atender y resolver los temas sanitarios, sociales y ambientales de la humanidad en su conjunto.

En tal sentido, la Conferencia General de la Unesco en su trigésima tercera reunión celebrada en París en octubre de 2005 ha adoptado por aclamación la Declaración Universal sobre Bioética y Derechos Humanos, que trata de «las cuestiones éticas relacionadas con la medicina, las ciencias de la vida y las tecnologías conexas aplicadas a los seres humanos, teniendo en cuenta sus dimensiones sociales, jurídicas y ambientales».

El citado documento, sobre la base de que la instauración a nivel internacionalde principioséticos es másnecesariaquenunca, proporciona un marco de principios y de procedimientos que podrán servir de guía a los Estados en la formulación de sus políticas, legislaciones y códigos éticos, reconociendo la importancia de la libertad de la investigación científica desde el respeto y la protección de la dignidad de la persona y los derechos humanos. Igualmente tiene presente que la identidad de una persona comprende dimensiones biológicas, psicológicas, sociales, culturales y espirituales. El texto enuncia diversos principios y reglas, algunos ya consagrados, como el respeto de la privacidad y de la confidencialidad, el consentimiento informado, y la no discriminación ni estigmatización. Pero la noción de «responsabilidad social» (y salud) es novedosa, y de clara raíz latinoamericana, toda vez que fue lanzada desde las reuniones preparatorias y finales de construcción de la citada Declaración Universal, realizadas en Buenos Aires en el año 2004, por un grupo de representantes de países de la región, defendiendo vigorosamente la inclusión —además de las cuestiones biomédicas y biotecnológicas - de los temas sanitarios, sociales y ambientales. La misma precisa que el progreso de las ciencias y de las tecnologías debería fomentar el bienestar de las personas y de la especie humana, favoreciendo en particular el acceso a una atención médica de calidad y a los medicamentos esenciales, especialmente para la salud de las mujeres y los niños, «ya que la salud es esencial para la vida misma y debe considerarse un bien social y humano», acceso a una alimentación y abastecimiento de agua adecuados, entre otros bienes y servicios primordiales. 
II. LOS PRINCIPIOS BIOÉTICOS COMO TÓPICOS JURÍDICOS El iusfilósofo cordobés Camilo Tale ${ }^{9}$, en un artículo publicado en 1998, que mereció nuestro análisis crítico en ponencia presentada en las Primeras Jornadas Nacionales de Bioética y Derecho ${ }^{10}$, señala que clásicamente los principios han sido normas preceptivas: normas más universales que otras, fuentes de otras y, por ello, denominadas principios. Pero, agrega, en la bioética contemporánea los llamados principios no siempre son normas. En vez de tener índole imperativa, suelen funcionar como orientaciones. Por ello se opta por uno o por otro, ante tal o cual problema bioético, se elige uno para fundar la decisión y se deja de lado otro. A su criterio, las normas éticas para ser realmente eso - normas éticas - deben ser imperativas y no meras orientaciones opcionales para seleccionar una u otra a la hora de decidir en un caso. Y no solo han de ser imperativas, sino también universales en su alcance. Opina que la tesitura que proclama los principios bioéticos y los postula como fundamentos de las conclusiones bioéticas deriva en realidad de la denominada ética de situación. De acuerdo con el modo de concebir esta moralidad, debe resolverse caso por caso, sin atenerse a normas universalmente válidas. Para el citado autor, explícita o implícitamente, este modo de tratar los temas morales está muy presente en el discurso bioético actual. Es cierto, admite, que las circunstancias son premisas para tener en cuenta al tratar un caso ético, pero también que hay principios de vigencia incancelable. Afirma así que el plexo de ideas con pretensión regulativa bajo el rótulo de bioética proclama una tríada de principios cuya aplicación simultánea resulta imposible, y que sirven en realidad como estrategia discursiva para la cohonestación de cualquier conducta que tenga que ver con la vida y la muerte y que interese defender. Para Tale, no son genuinos principios éticos, ni siquiera tienen la calidad de postulados de una doctrina bioética, por su incapacidad para justificar un sistema coherente de conclusiones. No obstante, concluye, pueden operar eficazmente con fin persuasivo en el discurso bioético, cumpliendo el papel de tópicos, es decir, lugares comúnmente aceptados en los auditorios habituados a ellos. Funcionan como lugares retóricos que aprovechan la resonancia agradable de los términos (autonomía, beneficencia) para generar la ilusión de una justificación racional de conductas.

El propósito de nuestra respuesta entonces no fue debatir si los principios bioéticos - con directa referencia a los que ha consagrado la bioética principialista: principios de no maleficencia, beneficencia, autonomía

9 TALE, Camilo. «Los tres —o cuatro- "principios de la bioética”, ¿son válidos?». El Derecho, 179 (1998), p. 863.

10 TINANT, Eduardo. «Los principios bioéticos como tópicos jurídicos». Ponencia presentada en las Primeras Jornadas Nacionales de Bioética y Derecho. Facultad de Derecho y Ciencias Sociales de la Universidad de Buenos Aires. Buenos Aires: UBA/Cátedra Unesco de Bioética, 2000, pp. 13-23 (www.aaba.org.ar); Antología para una bioética jurídica, pp. 11-16. 
y justicia- revisten o no tal carácter, cuestión analizada por calificada doctrina, sino destacar que aun en el rol de tópicos, al que se intentaba reducirlos, pueden cumplir $-\mathrm{y}$ de hecho ello ha venido aconteciendo desde hace dos décadas - un señalado papel en la tarea de los órganos jurisdiccionales de resolver en justicia los casos bioético-jurídicos que les han sido planteados.

Recordamos que en la concepción aristotélica, los tópicos o lugares son «reglas o recetas, argumentaciones destinadas a proveer instrumentos eficaces» para la discusión dialéctica; la práctica del diálogo razonado, el arte de argumentar por interrogantes y respuestas sobre el modelo socrático. La doctrina contemporánea ha aproximado la tópica aristotélica a los principios generales del derecho configurando los tópicos jurídicos (los lugares específicos del Estagirita) que conciernen a materias particulares y se oponen a los lugares comunes que se utilizan en el discurso persuasivo en general. Su importancia está dada porque suministran razones que permiten descartar las soluciones que no son equitativas o razonables, en la medida en que estas últimas descuidan las consideraciones que estos lugares permiten sintetizar y que se integran en una visión global del derecho como ars aequi et boni.

Recurso a los tópicos jurídicos que, según puntualiza Chaim Perelman ${ }^{11}$, no se contrapone a la idea de un sistema de derecho, sino a la aplicación rígida e inflexible de las reglas y permite el desarrollo de argumentos y controversias, de modo que se pueda tomar una decisión reflexiva y satisfactoria después de haber evocado todos los puntos de vista. Gracias a los tópicos jurídicos, el juez dispone de una mayor libertad de interpretación de los textos legales, la cual, en lugar de conducir a la arbitrariedad, aumenta sus medios intelectuales para la búsqueda de una solución razonable, aceptable y equitativa. A la postre, como anota Gerhard Struck $^{12}$, la gran ventaja de los tópicos jurídicos consiste en que, en lugar de contraponer dogmática y práctica, permiten elaborar una metodología que se inspira en la práctica y guían los razonamientos jurídicos, de manera que, en lugar de contraponer el derecho a la razón y a la justicia, se esfuerzan en conciliarlos.

En razón de la naturaleza eminentemente problemática de la interpretación jurídica, el razonamiento jurídico se mueve en el campo del pensamiento tópico, esto es, de la dialéctica retórica, a partir de premisas verosímiles y razonables que posibilitan mediante una reflexión, asimismo razonable, obtener conclusiones verosímiles y aceptables, antes que sistemáticas o apodícticas. La tópica es entendida así como retórica (arte de la persuasión) o praxis de la argumentación. Los criterios con que 
son considerados los problemas en ejercicio del modo de pensar tópico, es decir, las premisas que a modo de endoxa constituyen el fundamento de la argumentación jurídica, son denominados por Theodor Viehweg ${ }^{13}$ siguiendo a Aristóteles, tópicos (del griego topoi). El autor define a estos como un conjunto de criterios que sirven como medio para encontrar la solución más conveniente a los problemas planteados. La función de los tópicos jurídicos o lugares específicos del derecho consiste, por lo tanto, en servir para la consideración de los problemas concretos, suministrando razones que contribuyen a encontrar su solución.

Los tópicos van apareciendo producto del tratamiento continuo de problemas jurídico-prácticos, a través de los cuales se van manifestando criterios que permiten resolver problemas análogos; los tópicos nacen, por consiguiente, de consideraciones concretas de cada caso. De tal forma, Viehweg propicia un tratamiento casuístico de los problemas jurídicos, tratando de hallar la solución para cada uno de ellos por medio de procedimientos de inducción y analogía con base en tópicos preexistentes y, en caso de que ello no sea procedente, creando nuevos tópicos. Como subraya Eduardo García de Enterría en el prólogo a la edición española de la citada obra de Viehweg, «la ciencia jurídica ha sido siempre, es y no puede dejar de ser, una ciencia de problemas singulares» ${ }^{14}$. Vale decir, una ciencia práctica, un saber prudencialretórico que en el ámbito del Poder Judicial deviene el arte de hallar la solución justa del caso concreto, lo debido a otro en una circunstancia determinada. Viehweg concluye así sobre la absoluta imposibilidad de encerrar el derecho en un sistema axiomatizado dentro del cual se pretenda lograr la solución a los casos de especie mediante derivaciones obtenidas de la aplicación de inferencias deductivas.

La justicia de nuestro país ha sabido asumir, en diversas causas de índole bioético-jurídicas, que, ante la existencia de conflictos de valores y de derechos, resulta inevitable jerarquizar alguno de los principios, valores o derechos en crisis en detrimento de otros, ya sea conforme al método de las compensaciones, sopesando cuidadosamente todas las circunstancias particulares del caso, tarea de armonizar derechos en la que se ha considerado como realmente importante, «encontrar respuestas sensatas y útiles a la vez, que también sean legítimas» ${ }^{15}$, o bien a la pretensión de corrección, en el marco del juicio de ponderación o «clearing de valores» ${ }^{16}$.

13 VIEHWEG, Theodor. Tópica y jurisprudencia. Madrid: Taurus, 1964, pp. 50, 129-130.

14 García de EnTERRía, Eduardo. «Prólogo». En ViehWEG, Theodor. Ob. cit., p. 12.

15 SAGÜÉS, Néstor Pedro. «Metodología para la enseñanza de los derechos humanos (en las facultades de derecho y en las escuelas judiciales)». La Ley, C (1995), 920.

16 ALEXY, Robert. Teoría de los derechos fundamentales. Traducción de Ernesto Garzón Valdés. Madrid: Centro de Estudios Constitucionales (CEPC), 2002, p. 152. 
De tal manera, la aplicación de uno de los principios bioéticos, lejos de acarrear la inevitable exclusión de sus pares, resulta ciertamente útil como instrumento para el abordaje de los problemas bioéticos (caracterizados por su conflictividad y carácter dilemático), aunque en la práctica resulta muchas veces dificultoso hallar una articulación concreta y armónica de tales principios — de facto encontrados- y su jerarquización ${ }^{17}$.

Según dijimos entonces, nunca antes el derecho se había encontrado con una problematización concreta de su ámbito de regulación tan ambivalente como la que plantean las nuevas biotecnologías — cuyos notables avances pueden comprometer y aun lesionar la dignidad de las personas y la protección de los derechos humanos-. Y que si el intérprete pretende seguir manejando las situaciones que se le presentan a tenor de las concepciones tradicionales, dejará amplios espacios de materias no resueltas, e insatisfechas las legítimas expectativas de los ciudadanos interesados. La secular ética deontológica, cognitivista, formalista y universalista, ha incidido para que el derecho construyera soluciones de corte universal —-basadas en postulados abstractos-, que no parecen adecuadas para el contexto (conexión lingüística) y la situación (conexión no lingüística) específicas de una eticidad concreta como la que requieren las nuevas cuestiones que plantea el desarrollo tecnológico en la ciencias de la vida y la atención de la salud.

Cabe replantear pues las soluciones a los conflictos y problemas -en particular los referentes a las nuevas ramas de las ciencias biomédicas y sus tecnologías conexas- en términos de una eticidad contextualizada y no como una mera confrontación de principios y sistemas morales. La construcción de un discurso que dé cuenta de estas realidades muy específicas de nuestro entorno vital pasa por la definición de fórmulas consensuadas que permitan ir elaborando soluciones éticas no abstractas ni de pretensión universalista. Las diferentes legislaciones tienen que dar solución a las nuevas situaciones planteadas, dejando de lado la discusión fundamentalista y las abstracciones jurídicas. Antes bien, deben abordar cada tema en aras de la definición de propuestas de acción que, en primer lugar, acepten solamente la ingeniería genética con fines terapéuticos y, segundo, no impongan deberes de conducta a quienes pudieran rechazar la obligación legal de acuerdo con sus convicciones morales.

Si se acepta ello, repetimos, no parece desacertado el camino que propone Jesús Esparza, «de una moral de principios a una eticidad contextual en la búsqueda de nuevas soluciones normativas para la realidad bioética 
de nuestros días» ${ }^{18}$. En todo caso se condice con nuestro anticipo de que los principios bioéticos — sin desmedro de tal condición — pueden asumir la modalidad especial de tópicos jurídicos a la hora en que se torna indispensable brindar tutela jurisdiccional oportuna y eficaz a determinadas situaciones límite.

Como se advierte, la cuestión examinada guarda analogía con la que encierra la aplicación de los principios generales del derecho, pues, ya se los considere presupuestos lógicos de la norma legislativa o principios superiores de justicia radicados fuera del derecho positivo y a los cuales este trata de darles encarnación en una circunstancia histórica concreta determinada, actuando como criterios valorativos fundantes devienen normas positivas, y no por esto pierden su carácter primigenio ni resulta posible en ciertas ocasiones su aplicación simultánea.

\section{LA BIOÉTICA JURÍDICA}

Se desprende de lo dicho que, a la bioética «empírica» (que define lo que es) sucede una bioética «jurídica» (que determina o se pronuncia sobre lo que debe ser), en cuya virtud cabe preguntarse, iesta forma de bioética constituye una «nueva juridicidad»? Convocado como discurso y praxis a la vez, el derecho puede y debe cumplir un papel fundamental en el ámbito de la bioética: a él le incumbe la tarea de elaborar y establecer normas que permitan regular de modo colectivo los nuevos conflictos bioéticos y, planteados concretamente estos, darles ajustada y oportuna resolución. La ética por sí sola no alcanza para asegurar el respeto de la persona y la vigencia irrestricta de los derechos humanos. Pero urge aclarar que tampoco el derecho tiene la fuerza suficiente si - a partir de él- no se ejerce el poder político necesario con el fin de conjurar las amenazas que representan los nuevos intereses creados. Más aun, si no opera un cambio de paradigma ético y científico que permita plasmar una nueva y fructífera alianza entre las ciencias y la filosofía, la técnica y las humanidades, reclamada por Rensselaer Van Potter —en su libro Bioethics: Bridge to the Future-, al conjugar por primera vez a comienzos de la década de 1970 el término bioética.

En esa inteligencia son indispensables una mayor interactividad entre tales disciplinas y sus principios, otorgando un rol más activo al derecho, no para detener el desarrollo de las nuevas tecnologías biomédicas, sino para orientarlo, regularlo y controlarlo y, llegado el caso, prohibir determinadas prácticas contrarias a la dignidad humana, las libertades fundamentales y los derechos humanos. Desde una perspectiva regional latinoamericana, dicha construcción participativa debe acentuar 
la superación de las dificultades que atraviesan grandes grupos de población para alcanzar el debido estándar en la protección de su salud y calidad de vida.

Solo así cobrará sentido el axioma latino impetrado en el pórtico del presente: «Las causas de diverso género que convienen en un mismo acto, se causan mutuamente».

La noción de «bioética jurídica» — con la que hemos procurado responder aquel interrogante desde el año 2000 en sucesivos trabajos, y la Maestría, carrera de posgrado de la Facultad de Ciencias Jurídicas y Sociales de la Universidad Nacional de La Plata que actualmente dirigimos - difiere de vocablos a los que ha acudido buena parte de la doctrina, al calificar o entender esta forma de bioética como una «nueva juridicidad», tales como:

1. «Bioderecho», en la inteligencia de que: a) se trata de una «rama jurídica transversal», que no significa negación, pero sí complemento de otras ramas del derecho (Ciuro Caldani); b) el «bioderecho» representa un paso posterior, dado el asincronismo entre la ciencia y el derecho: «de la bio-éthique au bio-droit», «aprés l'éthique la loi» (Nairinck, Lavialle; id. Messina de Estrella Gutiérrez); c) configura una nueva disciplina científica: «derecho biomédico o bioderecho», cuya específica metodología le diferencia de la bioética; normativa basada en el estudio de los datos biológicos, valores aportados por el debate ético, construcciones doctrinales y jurisprudenciales sobre los derechos humanos (Romeo Casabona, I.M. Sánchez).

2. «Biojurídica», por considerarla: d) «una nueva rama del derecho», que tiene que ver directamente con la aplicación de los avances científicos a los seres humanos (Vila-Coro); e) «la respuesta desde el mundo jurídico al surgimiento de la bioética» (D'Agostino); f) un «término más extendido», que expresa que «es preciso un debate específicamente jurídico, toda vez que de discusiones esencialmente morales no se derivan soluciones eminentemente jurídicas» (Serrano Ruiz-Calderón); g) una «rama especial del ordenamiento políticojurídico que versa sobre la investigación de la vida humana y el cuidado de la salud» (Sánchez-Bayón).

3. Cuadro al que cabe sumar la posición de los que propician la ampliación del encuentro entre bioética y derecho, mediante: h) la profundización del diálogo entre «bioética» y «derechos humanos», sin necesidad de recurrir al neologismo «bioderecho» (Hooft); i) el dictado de reglas de convivencia «no solo desde la dicotomía de lo bueno y lo malo (propia de la bioética), sino también desde la dualidad de lo justo e injusto (específica del derecho)» (Dalla Torre: Multietnicitá bioetica e diritto); j) lo caracterizan como una «bioética 
con rasgos jurídicos»: una especie de «enrejado jurídico» de las ciencias de la salud (Broekman); k) o, aun con una significación limitada, se refieren a la «juridificación de la bioética», desde el momento en que esta es abordada desde el ángulo jurídico (Atienza); l) o se refieren a la «juridización de la bioética», expresada en el progresivo crecimiento de los dominios regulados por el derecho, a costa de las demás relaciones sociales (Callens); m) o bien conciben una «bioética de los derechos humanos», como una teoría de teorías que permite demarcar el campo de la bioética a partir en modo indisociable del respeto a la moral universal de los derechos humanos (Tealdi).

Sea cual fuere el criterio que se adopte, resulta innegable la importancia del derecho en y desde la bioética y de la propia bioética en el derecho. A condición de no incurrirse en una «formalización» de la bioética, es decir, la reducción a formas jurídicas de fenómenos que son esencialmente dinámicos e interdisciplinarios, manteniendo abierto el diálogo pluridisciplinar inherente a la bioética. Podrá distinguirse así la «bioética jurídica» de otras modalidades, puesto que la misma no tiene por objeto la transformación de la bioética en una simple nueva rama del derecho, ni tampoco convertirse en un mero marco normativo de las ciencias de la vida y de la salud — minus legítimamente reprochado a aquellas-, sino la comprensión y necesaria regulación jurídica de los temas y problemas bioéticos tendiente al reconocimiento y la tutela eficaz de la dignidad humana y los derechos y libertades fundamentales relacionados con el avance de tales ciencias y sus tecnologías conexas, lo cual es algo muy distinto.

De tal forma, la bioética jurídica constituye la rama de la bioética que estudia la regulación jurídica y las proyecciones y aplicaciones jurídicas de la problemática bioética: las ciencias biomédicas y sus tecnologías conexas y su incidencia en el ser humano y, al mismo tiempo, una reflexión crítica sobre las crecientes y fecundas relaciones entre la bioética y el derecho (a escalas nacional, regional e internacional).

\section{PRINCIPIOS JURÍDICOS Y PRINCIPIOS BIOÉTICOS: ¿SEPARACIÓN O VINCULACIÓN?}

Abordaremos el aspecto central de nuestra tarea de acuerdo con una concepción epistemológica materialista, aquella que plantea como exigencia fundamental distinguir dos momentos presentes en la búsqueda del conocimiento científico, los que hacen al estudio interno del objeto: sus categorías originarias (momento estático); y al estudio externo del mismo: investigando su génesis en función de su inserción en el conjunto de relaciones y articulaciones de los distintos niveles de la formación social (momento dinámico), en cuya virtud la tarea del jurista debe centrarse no solo en estudiar cómo se construye el conocimiento 
jurídico, sino también en el análisis del proceso de producción de normas. Por sobre todo (aun por sobre la producción formal: la actividad del Parlamento o de la Administración) en la producción material que habilita y legitima el dictado de determinados cuerpos de leyes en situaciones históricamente determinadas, aprehendiendo el objeto de estudio — el derecho - a través de la suma de historia interna e historia externa ${ }^{19}$.

Es que solo se puede dar cuenta de la permanente reconstrucción del sistema jurídico que hacen sus intérpretes si entendemos el derecho -básicamente constituido por normas jurídicas, pero no solo por ellas-, captándolo en su proceso de producción antes que si nos acercamos a él como producto terminado. Ni norma de conducta ni conducta normada solamente. Es menester ahondar tales significados en la conducta normante (que incluye no solo al legislador, sino también el contexto social y político ${ }^{20}$.

Se podrá percibir así que las normas, si bien son por lo general un producto terminado, tienen un previo proceso de producción y un posterior y permanente proceso de resignificación que explica el por qué pueden adaptarse a tiempos siempre cambiantes a pesar de existir en textos generalmente fijos que tardan mucho más en modificarse que lo que tarda en cambiar la historia. El conocimiento que identifica la práctica y el saber de los juristas, cuyas premisas no son apodícticas, sino meramente plausibles, necesita construirlas y validarlas desde diversas esferas, en tanto los fenómenos signados por la complejidad ni son fácilmente domesticables, ni se encuentran sujetos a esquemas predictivos simplistas y lineales. Esta consideración de lo jurídico abre un espacio para lo contingente, lo opinable y lo discutible, quehacer intersubjetivo que permite la reconstrucción permanente del sistema normativo y su adaptación a tiempos históricos siempre cambiantes. Ello explica por qué los llamados «críticos» tratan de ocuparse del derecho que manejan los operadores. Ese que, al decir de Carlos Cárcova ${ }^{21}$, es lo que la ley manda, pero también lo que los jueces interpretan, los abogados argumentan, los litigantes declaran, los teóricos producen, los legisladores sancionan o los doctrinarios critican, etcétera y también el que, entre los ciudadanos, opera como sistema de representaciones.

Cabe considerar el derecho así como una materia textual, susceptible de ser analizada desde una perspectiva que no se agota en la mera escritura de la ley, sino que intenta captar la producción de sentido

19 AsEFF, Lucía María. Argumentación jurídica y semiosis social. Prólogo de Mario A. Portela. Rosario: Juris, 2003, pp. 30-37.

20 TINANT, Eduardo. «Una investigación lógica sobre la normación jurídica». Comunicaciones, Primer Congreso Internacional de Filosofía del Derecho. Instituto de Cultura Jurídica, Facultad de Ciencias Jurídicas y Sociales (UNLP). La Plata, 1982, tomo II, pp. 439-456.

21 CÁrcova, Carlos. La opacidad del derecho. Citado en AsefF, Lucía María. Ob. cit., p. 118. 
social que se inviste en las diversas manifestaciones de esta disciplina y que abarca, además, las distintas prácticas sociales vinculadas a lo jurídico o por él afectadas ${ }^{22}$.

Por esta senda se advierte, asimismo, la necesidad de ampliar los marcos teórico-prácticos para poder transitar la interdisciplinariedad. Y para esto es menester incorporar estudios antropológicos, psicológicos, sociológicos, económicos, y cuantos más sean necesarios, para mejor abarcar el objeto sin caer en la banalidad y el esoterismo. Contexto en el que, agregamos, no puede ni debe faltar la bioética desde sus principios.

A la luz de lo anteriormente expresado, resulta evidente no ya la separación, sino la vinculación —acaso algo más que esta, según veremos- que guardan los principios jurídicos y los principios bioéticos entre sí. Tomemos un par de ejemplos; el primero, el principio de dignidad humana.

En el ámbito de la bioética, ubicada la persona en el centro de la escena, cabe resaltar que «ser persona» equivale a «ser digno»: dignidad ontológica (intrínseca, la que hace referencia a su ser) y dignidad ética (la que atañe a su obrar). De tal forma, la idea de dignidad humana no es un mero principio entre otros. Constituye el punto de referencia decisivo para entender la actividad humana en general -médica en particular - y, en definitiva, de todas las instituciones jurídicas, políticas y sociales (cual necesario telón de fondo - unificador- de las mismas) ${ }^{23}$.

En el ámbito del derecho, de modo similar, el principio de dignidad humana cumple el papel de fijar límites al derecho positivamente vigente (función ético-jurídica y jurídico-constitucional) cuando la libre autodeterminación de un sujeto es éticamente legítima en un caso concreto. De tal forma, funciona como garantía negativa cuando prohíbe determinados comportamientos notoriamente indignos para la condición humana: verbigracia la tortura, los tratos discriminatorios; en tanto que lo hace como garantía activa al afirmar positivamente el desarrollo integral de la personalidad humana ${ }^{24}$.

Algo parecido acontece con la protección y atención de la salud, bien colectivo y principio (principium) y a la vez derecho humano a la salud (concretum) $)^{25}$.

23 TINANT, Eduardo. Bioética jurídica, dignidad de la persona y derechos humanos. Buenos Aires: Dunken, 2007, pp. 9-14, 124-136.

24 SAGÜÉS, Néstor Pedro. «Dignidad de la persona e ideología constitucional». Jurisprudencia Argentina, IV, 904 (1994), pp. 904-906.

25 TINANT, Eduardo. Antología para una bioética jurídica, pp. 127-136, 151-159; Bioética jurídica, dignidad de la persona y derechos humanos, pp. 137-160; «Bien colectivo y decisión judicial». En TEALDI, Juan Carlos (dir.). Diccionario latinoamericano de bioética. Bogotá: Unesco/Red Latinoamericana y del Caribe de Bioética/Universidad Nacional de Colombia, 2008, pp. 387-390.

PRINCIPIOS JURÍDICOS Y PRINCIPIOS BIOÉTICOS. SEPARACIÓN, VINCULACIÓN, INTEGRACIÓN

LEGAL AND BIOETHICAL PRINCIPLES. SEPARATION, CONNECTION, INTEGRATION 
Podrá apreciarse así cómo la tétrada de principios de la bioética principialista — no maleficencia, beneficencia, autonomía, justicia- da cuenta de una de tales confluencias, en tanto que en la esfera jurídica la protagonizan los derechos constitucional, administrativo, penal, civil, a la luz de la moderna concepción de los derechos humanos que enarbola el derecho internacional de los derechos humanos ${ }^{26}$, resultando aplicable, entre otros tratados así consagrados, el Pacto Internacional de Derechos Económicos, Sociales y Culturales, PIDESC, cuyo artículo 12 reconoce el «derecho de todas las personas a disfrutar del más alto nivel posible de salud física y mental, así como el deber de los Estados parte de procurar su satisfacción». Garantiza ese derecho mediante el desarrollo de un «plan de acción para reducir la mortalidad infantil, lograr el sano desarrollo de los niños y facilitarles ayuda y servicios médicos en caso de enfermedad», en concordancia con el artículo 2, inciso 1, por el que los Estados parte se han «obligado hasta el máximo de los recursos» de que dispongan para lograr progresivamente la plena efectividad de los derechos reconocidos en dicho pacto.

La no maleficencia, como los restantes principios, se derivan de la dignidad humana, metaprincipio que no precisa de justificación previa porque es auténticamente constitutivo, como dijimos. Evitar daños en el ser humano es adoptar la no maleficencia como principio en el ejercicio del respeto a la dignidad, cumpliendo con el imperativo que manda garantizar la inviolabilidad de la persona. De tal modo, el deber pasivo de no maleficencia (abstenerse de hacer el mal) normalmente precede al deber activo de beneficencia (hacer o promover el bien o el bienestar). Principio caro a la tradición médica hipocrática — pues la no maleficencia procura el mayor beneficio para el paciente, su «mejor interés», sin ocasionarle daño-, y luego latinizado como primun non nocere guarda evidente analogía con el principio jurídico alterum non laedere $^{27}$. Como se ha dicho: «El no dañar es un principio de vigencia universal a través del tiempo, pero antes tenía un contenido singular y ahora, en cambio, constituye uno de los pilares del orden social ${ }^{28}$.

\section{V. ¿HACIA UNA «HETEROINTEGRACIÓN»POR DESARROLLO DE PRINCIPIOS?}

Llegados a este punto, entendemos que hay algo más que vinculación entre los principios jurídicos y los principios bioéticos. Se trata de una integración interdisciplinaria, tendiente a instrumentar la cooperación entre ambos. Integración que es, por lo tanto, heterointegración, 
y puede producirse por desarrollo de principios comunes y afines. Para ello, es menester construir un saber teórico-práctico compartido, compatibilizando el conjunto de datos y los términos del tema y/o problema escogido.

En el orden jurídico hay relaciones o situaciones reguladas y otras que se hallan excluidas de la regulación. El legislador es quien las incluye o excluye, por diferentes motivos. Se ha hablado así en la doctrina de la existencia de lagunas de la ley, falta una ley que pueda resolver el supuesto planteado. Y en la existencia de lagunas del derecho, no existen ni ley ni costumbre ni principio que puedan resolver el caso concreto, si bien tales lagunas no están admitidas por lo general en los ordenamientos jurídicos, en virtud del principio de inexcusabilidad de los tribunales de justicia, por el cual estos deben conocer, juzgar y hacer ejecutar lo juzgado aun no habiendo ley que resuelva la contienda sometida a su competencia, pudiendo para ello apoyarse en los principios generales del derecho y la equidad natural. Tal zona fronteriza o gris o poco determinada o incierta, es atraída por la normatividad que regula. Si el ordenamiento no es completo hay dos procedimientos, denominados «de heterointegración»y «de autointegración» ${ }^{29}$.

La autointegración implica que es llevada a cabo por el mismo ordenamiento, en la misma fuente dominante, en cualquiera de sus gradas, o yendo mínimamente a fuentes distintas. La heterointegración se efectiviza por medio de dos vías: a) propia, acudiendo el juez a ordenamientos diversos; y b) impropia, recurriendo a fuentes distintas de la fuente dominante (ley, por caso), como la costumbre o el derecho judicial (que da facultad de creación al juez) o de los sistemas que permiten al juez fallar en equidad.

En la heterointegración propia, pues, se busca la solución en diversos ordenamientos, tomando de ellos principios generales de carácter metapositivo, vale decir, se intenta la superación de las lagunas existentes en el ordenamiento jurídico mediante la aplicación de alguna norma o principio que pertenece a otro ordenamiento totalmente distinto de aquel en que tales lagunas se han producido. Pero también cabe acudir a la heterointegración en el supuesto de un concepto normativo indeterminado, que requiere determinación por precisión o reglamentación de normas o, como aquí postulamos, por desarrollo de principios. Tal concurrencia no solo admite, sino que permite una solución justa.

Por ende, es pertinente aplicar el procedimiento de heterointegración cuando los principios bioéticos que trascienden al derecho positivo, 
no obstante, lo enriquecen y complementan en la solución del caso concreto. Lejos de una presión separadora (fuerza centrífuga) tal búsqueda impulsa una marcada convergencia (fuerza centrípeta). En dicho proceso de heterointegración interactúan mutuamente el derecho en la bioética y la bioética en el derecho, requiriendo la homogeneización normativa correspondiente una especial participación de los juristas

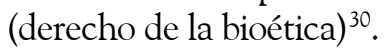

A fin de verificar lo sostenido, veamos someramente el tema de la libertad de la persona en ambas esferas, jurídica y bioética, y su íntima conexión con la dignidad, la integridad y la autonomía de la persona.

En el ámbito del derecho, la persona tiene el derecho de realizar actos que no perjudiquen a terceros ${ }^{31}$. Esfera privada de la que emana la libertad jurídica, libre de coacciones o injerencias indebidas, que consiste en ser dueño del propio destino y que contempla la seguridad de la persona en su propia vida, en su integridad física y moral, y en todas las manifestaciones de la libertad jurídica individual, la libertad de conciencia (y su faz negativa, la objeción de conciencia), de pensamiento, religiosa, de opinión y de expresión, así como otras libertades asimismo tuteladas.

En el ámbito de la bioética, la libertad se exhibe como autonomía personal: la persona en su condición de agente moral autónomo. Pero, aun cuando esta condición reviste enorme importancia, el derecho moral que genera no es absoluto, noción de autonomía que se vincula con las de dignidad de la persona e integridad de la persona. «El concepto de integridad de la persona sustenta el concepto de persona autónoma». Vale decir, se vulnera la integridad de la persona si no se respeta su dignidad ${ }^{32}$.

Autonomía (por su etimología griega), significa capacidad para gobernarse a sí mismo. La persona, como agente moral autónomo. Pero el derecho moral que genera no es absoluto, cuando este entra en conflicto con el de la integridad de otras personas surgen limitaciones a su propia autonomía. De tal manera, la autonomía es una capacidad de la persona total, pero no es el total de capacidades de una persona (autonomía $=$ tenencia) .

Integridad (del latín integer), significa totalidad, entereza o unidad intacta; totalidad fisiológica, psíquica y espiritual del individuo. No admite grados, ni se puede perder; integridad $=$ salud (integral). Por el contrario, desintegración $=$ enfermedad, se produce la ruptura en una

30 TINANT, Eduardo. Bioética jurídica, dignidad de la persona y derechos humanos, pp. 119-136, 149-160.

31 Artículo 19 de la Constitución Nacional: «Ningún habitante de la Nación será obligado a hacer lo que no manda la ley, ni privado de lo que ella no prohíbe».

32 PeLLEGRINO, Edmund. «La relación entre la autonomía y la integridad en la ética médica». Boletín de la Organización Panamericana de la Salud, 527 (1990), pp. 8-17. 
o más esferas, cada una con sus propias implicaciones éticas (corporales, psicológicas, axiológicas) (integridad $=$ atributo).

En el derecho a la integridad, pues, el bien jurídico tutelado es la integridad de la persona. Totalidad fisiológica, psíquica y espiritual del individuo. La correcta ordenación de las partes del todo: la armonía entre las diversas dimensiones de la existencia humana.

Cabe apreciar así claros ingredientes bioéticos en el derecho a la integridad. La integridad de una persona se expresa en una situación equilibrada entre los elementos corporales, psicosociales e intelectuales y axiológicos de su vida (cada una de las tres esferas tiene sus propias implicaciones éticas). Ningún elemento es desproporcionado en relación con los demás. Cada uno toma la delantera cuando el bien conjunto así lo exige. Cada uno cede ante el otro por el bien del conjunto. Pero ello de ningún modo significa inconexidad. La integridad tiene dos sentidos en la ética médica (también los tiene de modo parecido en la ética de la abogacía, respecto del cliente y del abogado), como derecho moral (integridad de la persona: del paciente y del médico) y como virtud o hábito moral (ser una persona de integridad).

Como resultado de ello, los principios de intimidad, autonomía y respeto a la integridad de la persona son necesarios, pero no totalmente suficientes para preservar la integridad de la persona. Lo indispensable es la persona de integridad, la persona de entereza moral que respete los matices y las sutilezas del derecho moral a la autonomía. Por cuya razón, se vulnera la integridad del individuo si su reconocimiento depende de algún criterio externo y no del valor intrínseco del mismo, vale decir, si no se respeta la dignidad de la persona y su concreción jurídica específica, el derecho humano en cuestión. Por ejemplo, en el marco de la ética al final de la vida, el derecho humano a la salud que, además de las cuestiones referidas a la protección de la salud y la atención sanitaria (propias de la medicina curativa o restaurativa), involucra la toma de decisiones sobre el cuidado de la persona (propias de la medicina posventiva o paliativa); ambas integrando el cuadro de la posmedicina ${ }^{33}$.

\section{CONCLUSIONES}

1. Aun cuando la ética y el derecho se ocupan del comportamiento humano tanto individual, como social, no es fácil establecer el o los modos en que se relacionan entre sí (separación/vinculación). Dificultad atribuible por extensión a la bioética —en su «núcleo duro» una parte de la ética, mas no toda la ética, y a la vez, si se 
quiere paradójicamente, algo más que ética-, y cuya creciente importancia autoriza a considerarla en dicho debate.

2. Desechada prontamente la tesis de la separación, a nuestro juicio hay algo más que vinculación — la otra tesis tradicionalentre los principios jurídicos y los principios bioéticos. Se trata de integración, una integración interdisciplinaria tendiente a instrumentar la cooperación entre ambos. Tal integración, en rigor, heterointegración, puede producirse por desarrollo de principios comunes y afines. Para ello, es menester construir un saber teórico-práctico compartido, compatibilizando el conjunto de datos y los términos de los temas y/o problemas escogidos.

3. En la heterointegración (propia) se busca la solución en diversos ordenamientos, acudiendo entonces el juez a principios generales de carácter metapositivo, ya sea en procura de la superación de lagunas jurídicas existentes en el ordenamiento jurídico mediante la aplicación de alguna norma o principio perteneciente a otro ordenamiento totalmente distinto de aquel en que tales lagunas se han producido, o bien, en el supuesto de un concepto normativo indeterminado, que requiere determinación por precisión o reglamentación de normas o, como en nuestro caso, por desarrollo de principios, concurrencia que no solo admite, sino que permite una solución justa.

4. Resulta pertinente la heterointegración en particular cuando los principios bioéticos enriquecen y complementan los principios jurídicos en la solución del caso concreto, de modo coincidente con lo que hemos dicho en el punto IV sobre los principios bioéticos como tópicos jurídicos.

5. En el proceso de heterointegración entre los principios jurídicos y los principios bioéticos, interactúan mutuamente el derecho en la bioética y la bioética en el derecho, requiriendo su homogeneización normativa una especial participación de los juristas (derecho de la bioética).

6. Convocado como discurso y praxis a la vez, el derecho puede y debe cumplir un papel fundamental en el ámbito de la bioética: a él le incumbe la tarea de elaborar y establecer normas que permitan regular de modo colectivo los nuevos conflictos bioéticos y, planteados concretamente estos, darles ajustada y oportuna resolución. La ética por sí sola no alcanza para asegurar el respeto de la persona y la vigencia irrestricta de los derechos humanos. Pero urge aclarar que tampoco el derecho tiene la fuerza suficiente si —a partir de él— no se ejerce el poder político 
necesario con el fin de conjurar las amenazas que representan los nuevos intereses creados.

7. El derecho constituye una materia textual, susceptible de ser analizada desde una perspectiva que no se agota en la mera escritura de la ley, sino que intenta captar la producción de sentido social que se inviste en las diversas manifestaciones de esta disciplina y que abarca, además, las distintas prácticas sociales cercanas a lo jurídico o por él afectadas. Senda por la que asimismo se advierte la necesidad de ampliar los marcos teóricoprácticos para poder transitar la interdisciplinariedad, para lo cual es menester incorporar estudios antropológicos, psicológicos, sociológicos, económicos, y cuantos más sean necesarios, para mejor abarcar el objeto, contexto en el que no puede ni debe faltar la bioética desde sus principios.

PRINCIPIOS

JURÍDICOSY

PRINCIPIOS

BIOÉTICOS.

SEPARACIÓN, VINCULACIÓN, INTEGRACIÓN

LEGAL AND

BIOETHICAL

PRINCIPLES.

SEPARATION,

CONNECTION,

INTEGRATION 